\title{
Polyvinylalcohol Stabilizes Anthocyanins of Red Wine in the Solid Phase but Not in the Aqueous Phase
}

\author{
Wataru Sakamoto $^{{ }^{*}}$, Takashi Kanehira², Hirohisa Hongou ${ }^{2}$, Kozo Asano ${ }^{3}$ \\ ${ }^{1}$ Serotec Laboratory, Ebetsu, Japan \\ ${ }^{2}$ Division of Preventive Dentistry, Graduate School of Dental Medicine, Hokkaido University, Sapporo, Japan \\ ${ }^{3}$ Division of Applied Bioscience, Research Group of Molecular Bioscience, Graduate School of Agriculture, \\ Hokkaido University, Sapporo, Japan \\ Email: ${ }^{*}$-sakamoto@serotec.co.jp, ${ }^{*}$ sakamoto@den.hokudai.ac.jp
}

Received 10 July 2015; accepted 21 August 2015; published 25 August 2015

Copyright (C) 2015 by authors and Scientific Research Publishing Inc.

This work is licensed under the Creative Commons Attribution International License (CC BY).

http://creativecommons.org/licenses/by/4.0/

(c) (i) Open Access

\begin{abstract}
Monomeric anthocyanins exhibit color variations at different $\mathrm{pH}$, but they are highly unstable at physiological pH. To improve the stability, the effects of polyvinylalcohol on the anthocyanins of young red wine prepared from Cambell Early grapes were examined in aqueous solution and in the solid phase on a cotton swab ${ }^{\circledR}$ and inert materials. Cyanidin-3-glucoside and malvidin-3-glucoside represented approximately $43.6 \%$ of total anthocyanins in the red wine. The anthocyanins decreased to $11.3 \%$ of the initial amount in aqueous solution at physiological $\mathrm{pH}$ after storage for $\mathbf{6 0}$ days at room temperature. On the other hand, from $66.9 \%$ to $87.2 \%$ remained in the solid phase on a cotton swab ${ }^{\circledR}$ and polypropylene membrane in the presence of polyvinylalcohol. The stability of the anthocyanins increased with the concentration of polyvinylalcohol in the solid phase but not in the aqueous solution. The anthocyanins were found to be condensed and immobilized in the complexes of anthocyanins and polyvinylalcohol on the polypropylene membrane by phase-contrast microscopy analysis. The anthocyanins in the cotton swab ${ }^{\circledR}$ displayed color variations when dipped into different $\mathrm{pH}$ buffer solutions. These results suggest that anthocyanins from red wine stabilized in the solid phase by polyvinylalcohol can be used as a visual indicator of $\mathrm{pH}$.
\end{abstract}

\section{Keywords}

Red Wine, Anthocyanins, Stability, Aqueous Phase, Solid Phase, Polyvinylalcohol

\footnotetext{
${ }^{*}$ Corresponding author.
}

How to cite this paper: Sakamoto, W., Kanehira, T., Hongou, H. and Asano, K. (2015) Polyvinylalcohol Stabilizes Anthocyanins of Red Wine in the Solid Phase but Not in the Aqueous Phase. Advances in Biological Chemistry, 5, 215-223. 


\section{Introduction}

Anthocyanins are natural, water-soluble, nontoxic pigments displaying a variety of colors from orange to blue according to the $\mathrm{pH}$ in aqueous solution [1]. In general, the main monomeric anthocyanins in red wines are the 3-O-monoglucosides of the six free anthocyanins, pelargonidin-3-glucoside, cyanidin-3-glucoside, delphinidin-3-glucoside, peonidin-3-glucoside, petunidin-3-glucoside and malvidin-3-glucoside [2]. Their ionic nature enables changes of the molecular structure according to the prevailing $\mathrm{pH}$, resulting in different colors and hues at different $\mathrm{pH}$ values [1]-[3]. Thus, the changes of color of anthocyanins are thought to be useful as a visual indicator of $\mathrm{pH}$, although there is no report on the visualization of clinical $\mathrm{pH}$ in body fluids such as saliva and nasal secretion using anthocyanins. This is because monomeric anthocyanins in red wine are unstable depending on various factors such as their structure, concentration, the composition of the solution, $\mathrm{pH}$ value, oxygen, storage temperature and time [4] [5]. Recently, Bimpilas et al. reported that during 1 year of storage monomeric anthocyanins declined by almost tenfold, probably due to polymerization reactions and copigmentation [4]. Therefore, we tried to extract anthocyanins from young red wine made using Cambell Early grapes in order to obtain an abundance of monomeric anthocyanins as reported by Mateus et al [5]. On the other hand, it is well known that polyvinylalcohol, which contains many hydroxyl groups, protects their active ingredients from moisture, oxygen and other environmental components [6]. In addition, it is easy to prepare, has good mechanical properties, excellent chemical resistance, and film-forming ability [7]-[9]. Conte et al. recently reported a new technique for the immobilization of lysozyme, active against gram-positive bacteria, without comprising its activity [10]. Interestingly, Singh and Mishra recently demonstrated that the optimized methods of extraction of two primary emitting pigments from their corresponding plant sources were simple, cheap and fairy green using anthocyanin, curcumin and polyvinylalcohol [11]. However, it is not yet clarified by which mechanism polyvinylalcohol stabilizes anthocyanins in the solid phase, although we previously reported that anthocyanins from red wine stabilized by polyvinylalcohol [12]. Therefore, the combination of polyvinylalcohol and young red wine was expected to stabilize anthocyanins, probably due to formation of hydrogen bonds from the hydroxyl group of polyvinylalcohol and protonated flavylium cations of the anthocyanin [13]. We first compared the stability of anthocyanins in the aqueous phase and the solid phase and attempted to stabilize anthocyanins in the solid phase using a combination of young red wine and polyvinylalcohol. Considering these points, we finally attempted to prepare stable anthocyanins as a visual of indicator $\mathrm{pH}$ in a cotton swab ${ }^{\mathbb{B}}$ based on the changes of color of the anthocyanins from young red wine.

\section{Materials and Methods}

\subsection{Chemicals and Reagents}

All chemicals and reagents used in this study were of analytical or HPLC grade. Malvidin-3-glucoside chloride and cyanidin-3-glucoside chloride were purchased as standards from Tokiwa Phytochemical Co. (Chiba, Japan).

\subsection{Extraction of Anthocyanins from Grapes}

Extraction of anthocyanins was carried out by winemaking using Cambell Early grapes. After washing with tap water, a total mass of $10 \mathrm{~kg}$ of grapes was crushed and the resultant $8 \mathrm{~L}$ of grape must was transferred to a plastic fermentation jar. Alcohol fermentation was continued for two weeks at room temperature (RT) with twice daily pumping. After removing skins and seeds by gauze filtration, fermentation was further performed for two weeks at RT. After centrifugation at $2000 \mathrm{rpm}$ for $10 \mathrm{~min}$, the red wine ( $\mathrm{pH} 3.5)$ was stored at $-20^{\circ} \mathrm{C}$ in a freezer until used as anthocyanin solution. The content of alcohol and $\mathrm{pH}$ were measured by enzymatic determination using a Roche Kit (R-Biopharm AG, Darmstadt, Germany) and a Horiba pH meter (F-52; Horiba Co., Kyoto, Japan), respectively.

\subsection{Measurement of Total Anthocyanin}

The concentration of monomeric anthocyanin was measured using the pH differential method [14], except as otherwise described. The anthocyanin in 96-well microplates was quantified at $540 \mathrm{~nm}$, using cyanidin-3-glucoside chloride as the standard, because the wavelengths of the maximum absorbances for anthocyanin species had been reported to be $498 \mathrm{~nm}$ to $540 \mathrm{~nm}$ at pH 2.0 [14]. To do this, an aliquot of a $100 \mu \mathrm{L}$ sample was added to a 
microtube (1.5 mL; Ina-Optica Co., Osaka, Japan) containing $400 \mu \mathrm{L}$ of methanol in $1 \%$ hydrochloric acid. After vortexing for $10 \mathrm{sec}$, it was centrifuged at $8000 \mathrm{rpm}$ (Kubota 1120, Kubota Ltd., Osaka, Japan) for 3 min at RT. Then $300 \mu \mathrm{L}$ of the supernatant was added to a 96-well microplate (NunclonTM 167008; Nunc A/S, Denmark) and the total anthocyanin content was quantified at $540 \mathrm{~nm}$ using a microplate reader (Labsystems-Multiskan MS, Dainippon Pharm. Co., Japan).

\subsection{HPLC Analysis}

Analysis of anthocyanins was performed using a Shimadzu HPLC system (Shimadzu Corp., Kyoto, Japan) equipped with an LC-10ADvp HPLC pump, SIL-10ADvp automated sample injector, CTO-10Avp thermostatted column compartment, and SPD-10Avp detector. The column (ODS-120T; column size $25 \times 0.46 \mathrm{~cm}$, Toyo Soda Co., Japan) set at $40^{\circ} \mathrm{C}$ was eluted isocratically with $15 \%$ acetonitrile in $1 \%$ formic acid at a flow rate of $1.0 \mathrm{ml} / \mathrm{min}$ and anthocyanins were detected at $520 \mathrm{~nm}$.

\subsection{Stability of Total Anthocyanin in Aqueous Solution and the Solid Phase}

The anthocyanin concentrations at native $\mathrm{pH}(\mathrm{pH} 3.5)$ and $\mathrm{pH} 7.0$ adjusted with $4.0 \mathrm{M} \mathrm{NaOH}$ were $383 \mu \mathrm{g} / \mathrm{ml}$ and $330 \mu \mathrm{g} / \mathrm{ml}$, respectively. Samples were stored in microtubes and kept at RT without daylight. They were obtained at regular time intervals within a period of 60 days and the anthocyanins were measured by the microplate method. The stability of anthocyanin was expressed as the percentage of residual anthocyanin compared to the total anthocyanin content of each starting material. Regarding the stability of the anthocyanins in the solid phase, we used the anthocyanin of a $70 \mu \mathrm{L}$ (23 $\mu$ g anthocyanin) sample that penetrated a cotton swab ${ }^{\circledR}$ (length: $13.0 \pm 1.0 \mathrm{~mm}$; diameter: $4.2 \pm 0.1 \mathrm{~mm}$; cellulose content: $40 \mathrm{mg}$; capacity of volume retention: $120 \pm 10 \mu \mathrm{L}$; Sanritsu Co., Japan) and Bell oasis ${ }^{\circledR}$ (inert polymer; diameter: $6.2 \pm 0.1 \mathrm{~mm}$; thickness $3.0 \mathrm{~mm}$; capacity of volume retention: $100 \pm 5 \mu \mathrm{L}$; Teijin Company, Osaka, Japan). We also used a polypropyrene membrane (square: $2 \times 2 \mathrm{~cm}$; thickness: $0.2 \mathrm{~mm}$; Lihit Lab Co., Osaka, Japan) that did not have the capacity for volume retention, unlike the materials described above. Therefore, the anthocyanin solution was directly put onto the surface of the polypropyrene membrane (diameter: $8.4 \pm 0.2 \mathrm{~mm}$ ) and dried at room temperature. Unless otherwise stated, they were kept at room temperature for 60 days. Prior to evaluation of the stability of the anthocyanins, the anthocyanin in the solid phase was extracted using $3 \mathrm{ml}$ of methanol in 1\% hydrochloric acid three times every other day at room temperature. The stability was expressed as described above.

\subsection{Effect of Polyvinylalcohol on the Stability of Anthocyanin}

Polyvinylalcohol (polyvinylalcohol-1500, Wako Pure Chemical Co., Japan) was dissolved in distilled water at $60^{\circ} \mathrm{C}$ for one hour to obtain homogeneous $37.5 \mathrm{mg} / \mathrm{ml}$ solutions. After dilution with $10 \%$ ethanol, $400 \mu \mathrm{l}$ of polyvinylalcohol $(1.5 \mathrm{mg} / \mathrm{ml}-37.5 \mathrm{mg} / \mathrm{ml})$ was added to $200 \mu \mathrm{l}$ of red wine solution $(330 \mu \mathrm{g} / \mathrm{ml}$ anthocyanin at $\mathrm{pH}$ 7.0) in the experiment of aqueous solution and stored at room temperature. In the solid phase, $100 \mu \mathrm{l}$ of polyvinylalcohol solution $(12.5 \mathrm{mg} / \mathrm{ml}-37.5 \mathrm{mg} / \mathrm{ml})$ was penetrated into them and dried at room temperature for 3 days, and then $70 \mu \mathrm{l}$ of red wine (23 $\mu \mathrm{g}$ anthocyanin at $\mathrm{pH}$ 7.0) was penetrated into the solid phases. Regarding the polypropylene membrane, the each solution of polyvinylalcohol and anthocyanin was directly put onto the surface (diameter: $8.4 \pm 0.2 \mathrm{~mm}$ ), respectively.

\subsection{Analysis of Surface Morphology of Polyvinylalcohol-Red Wine Complex on the Polypropylene Membrane}

First, $100 \mu \mathrm{l}$ of polyvinylalcohol solution $(12.5 \mathrm{mg} / \mathrm{ml})$ was applied to a square $(2 \times 2 \mathrm{~cm})$ polypropylene membrane and dried at room temperature for 3 days, and then $70 \mu \mathrm{l}$ of red wine (14 $\mu \mathrm{g}$ of anthocyanin) was coated on the surface of the dried polyvinylalcohol membrane. The polyvinylalcohol-red wine complex was observed at $\times 400$ magnification by phase contrast microscopy using an FC-300Z/OL (Olympus, Tokyo, Japan) and photographed using Fuji film (Neopan Across 100; Fuji Film Co., Tokyo, Japan).

\subsection{Preparation of Cotton $\mathrm{Swab}^{\circledR}$ as a pH Indicator}

A cotton $\operatorname{swab}^{\circledR}$ was impregnated with $100 \mu$ l of polyvinylalcohol solution $(12.5 \mathrm{mg} / \mathrm{ml})$ and dried at room tem- 
perature for 3 days. It was further impregnated with $70 \mu \mathrm{L}$ (20.6 $\mu \mathrm{g}$ anthocyanin) of red wine and again allowed to dry for 1 hour at RT. The cotton swab ${ }^{\circledR}$ was lightly wrapped with aluminum foil until to use.

\subsection{Color Changes of Anthocyanins by pH}

Color changes of anthocyanins in the cotton $\mathrm{swab}^{\circledR}$ by $\mathrm{pH}$ were examined as follows. The cotton $\mathrm{swab}^{\circledR}$ was dipped into $100 \mu \mathrm{L}$ of $0.15 \mathrm{M}$ phosphate buffer (pH 5.5 - 8.0) and/or $0.15 \mathrm{M}$ carbonate/biscarbonate buffer (pH 8.5 - 9.5). After 2 minutes, visual color was photographed by PENTAX Digital Camera K-X (Hoya Corporation, Japan).

\subsection{Statistical Analysis}

Spearman's test and Kruskal-Wallis one-way analysis of variance were used for statistical analysis. Data were expressed as mean \pm standard deviation (SD). Differences were considered significant at $\mathrm{p}<0.05$.

\section{Results}

\subsection{HPLC Analysis of Anthocyanins in Red Wine}

After fermentation for four weeks, the red wine from the Cambell Early Grapes contained $404 \pm 45 \mu \mathrm{g} / \mathrm{ml}$ anthocyanin and $8.7 \% \pm 0.5 \%$ alcohol, with a $\mathrm{pH}$ of $3.5 \pm 0.2$. To determine the components of anthocyanin in the red wine, HPLC analysis was carried out using the authentic standards cyaniding-3-glucoside and malvidin-3glucoside. As shown in Figure 1, the red wine showed eight peaks, of which two were identified as cyanidin-

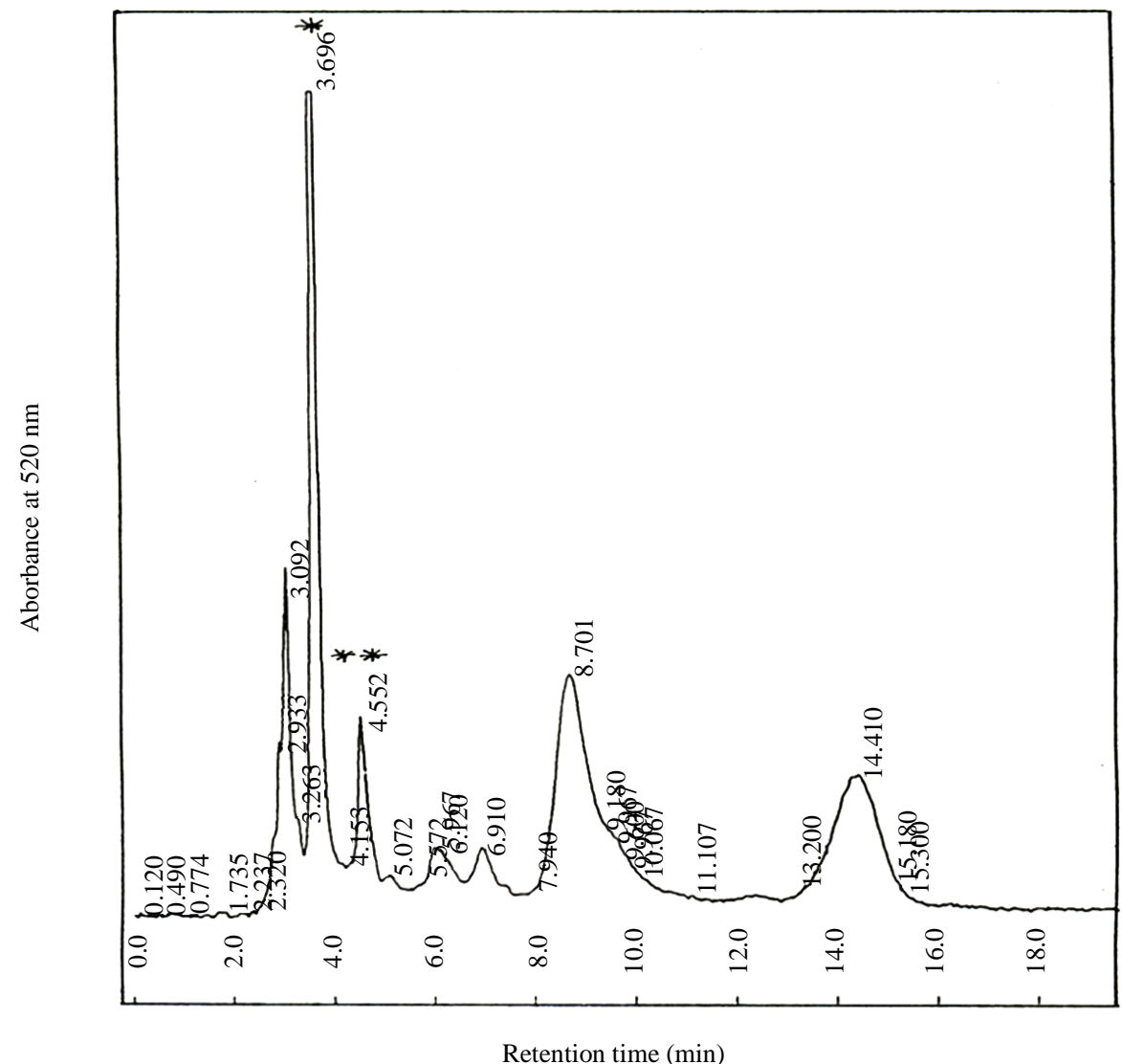

Figure 1. HPLC analysis of anthocyanins in red wine. Red wine (total anthocyanin: $5220 \mathrm{ng}$ ) was applied to an ODS-120T column. The anthocyanins were detected at $520 \mathrm{~nm}$. $*$ and ** were identified as cyanidin-3-glucoside and malvidin-3-glucoside from the retention times of their standards. Other experimental conditions are described in the text. 
3-glucoside and malvidin-3-glucoside by comparison with the authentic standards (retention times of 3.6 min and $4.5 \mathrm{~min}$, respectively). Cyanidin-3-glucoside accounted for $36.6 \%$ of the total anthocyanin and malvidin-3-glucoside $7.0 \%$. Two anthocyanins could not be identified, one with a retention time of $8.7 \mathrm{~min}$ (22.8\% of the total) and another with one of $14.4 \mathrm{~min}(17.9 \%)$.

\subsection{Stability of Total Anthocyanin of Red Wine in Aqueous Solution}

To investigate the stability of the total anthocyanin content in the aqueous solution at the native $\mathrm{pH}(\mathrm{pH} 3.5)$ and $\mathrm{pH}$ 7.0, its changes during storage at RT up to 60 days were investigated. Anthocyanin decreased slowly but continuously during storage at low $\mathrm{pH}(\mathrm{pH} 3.5)$. As shown in Figure 2, increasing the $\mathrm{pH}$ of the solution to 7.0 hastened the degradation of anthocyanin during the 60 days. Regarding the stability on the solid phase, it was investigated using the anthocyanin solution at $\mathrm{pH} 7$, because the anthocyanins were more unstable at $\mathrm{pH} 7.0$ than at the native $\mathrm{pH}$ (3.5) in the aqueous solution as described above. Table 1 showed that the residual anthocyanin in the aqueous phase was $11.3 \% \pm 3.0 \%$ of total anthocyanin after storage for 60 days at RT, but the solid phase ranged from $40.2 \%$ to $53.8 \%$ of total anthocyanin (Table 2). These results showed that the solid phase was more stable than the aqueous one ( $<0.05$ ), irrespective of the type of solid phase material.

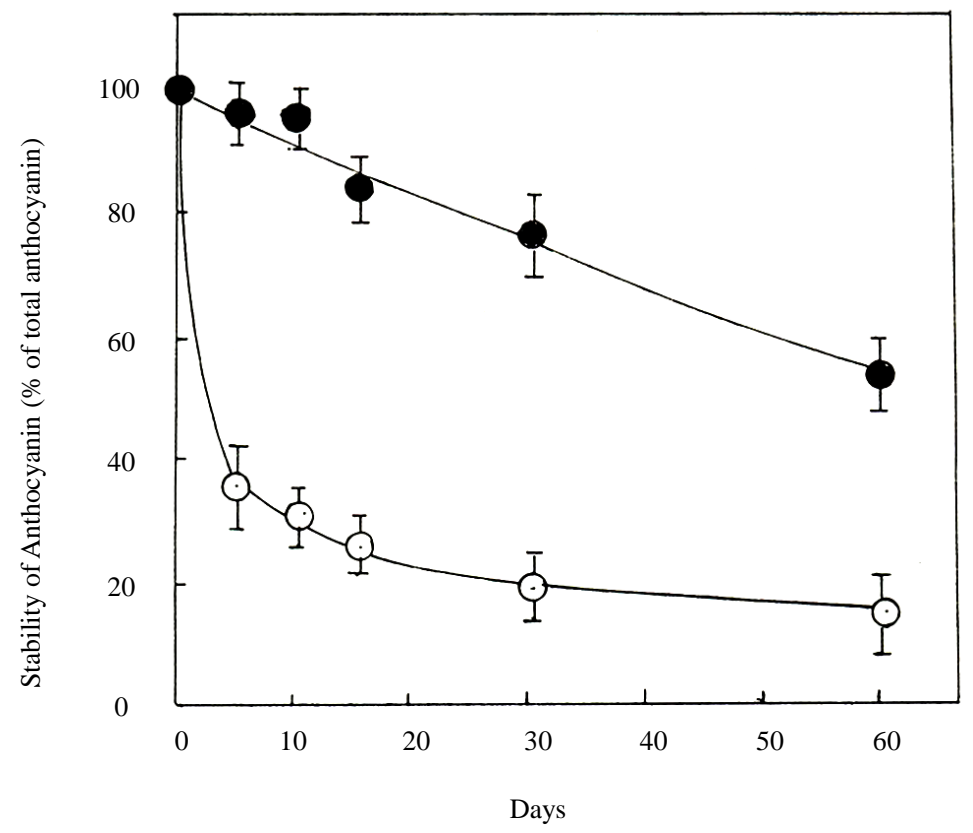

Figure 2. Stability of anthocyanin of red wine in aqueous solution. The stability was investigated during storage at RT. : native red wine $(\mathrm{pH} 3.5$, total anthocyanin content 383 $\mu \mathrm{g} / \mathrm{ml}$ ); $\bigcirc$ : red wine adjusted to $\mathrm{pH} 7.0$ (total anthocyanin content $330 \mu \mathrm{g} / \mathrm{ml}$ ). Other experimental conditions are described in the text. The data are expressed as the percentage of residual anthocyanin from total anthocyanin obtained in three experiments.

Table 1. Effect of polyvinylalcohol on the stability of anthocyanin in the aqueous phase.

\begin{tabular}{ccc}
\hline Polyvinylalcohol & \multicolumn{2}{c}{ Residual anthocyanin (\% of total anthocyanin) } \\
\hline $0 \mathrm{mg} / \mathrm{ml}$ & $18.4 \pm 4.0$ & 60 days \\
\hline 1.0 & $21.9 \pm 0.5$ & $11.3 \pm 3.0$ \\
8.3 & $25.8 \pm 3.0$ & $12.6 \pm 1.0$ \\
25 & $31.1 \pm 6.7$ & $14.4 \pm 1.7$ \\
\hline
\end{tabular}

Experimental conditions were described in the text. The data (mean $\pm \mathrm{SD}$ ) are expressed as the percentage of residual anthocyanin from total anthocyanin after storage of 30 and 60 days in three experiments. 
Table 2. Effect of polyvinylalcohol on the stability of anthocyanins in solid phase on various materials.

\begin{tabular}{ccccc}
\hline & \multicolumn{4}{c}{ Polyvinylalcohol (mg/solid phase) } \\
\hline Solid phase & 0 & 0.25 & 1.25 & 3.75 \\
& & Residual anthocyanin (\% of total anthocyanin) & \\
Cotton swab ${ }^{\circledR}$ & $40.2 \pm 2.2$ & $45.6 \pm 1.4$ & $62.7 \pm 3.8^{*}$ & $66.9 \pm 3.5^{*}$ \\
Inert polymer & & & & \\
Polypropyrene membrane & $44.5 \pm 2.8$ & $67.2 \pm 6.8$ & $80.0 \pm 4.4^{*}$ & $87.2 \pm 9.0^{*}$ \\
Bell oasis $^{\circledR}$ & $53.8 \pm 7.8$ & $87.3 \pm 9.5$ & $97.9 \pm 6.8^{*}$ & $101.7 \pm 14.3^{*}$ \\
\hline
\end{tabular}

$100 \mu$ l of polyvinylalcohol solution $\left(1.25 \mathrm{mg} / \mathrm{ml}-37.5 \mathrm{mg} / \mathrm{ml}\right.$ ) was penetrated into the solid phases (cooton swab ${ }^{\circledR}$ and Bell oasis ${ }^{\circledR}$ ) or applied on the surface of polypropyrene membrane (diameter: $8.4 \pm 0.2 \mathrm{~mm}$ ). After dry at room temperature for 3 days, $70 \mu \mathrm{l}$ of red wine (23 $\mu \mathrm{g}$ of anthocyanin at $\mathrm{pH}$ 7.0)) was penetrated the solid phases or applied on the surface of polypropyrene membrane. After storage for 60 days at room temeperature, residual anthocyanin was measured. The data (mean $\pm \mathrm{SD}$ ) are expressed as the percentage of residual anthocyanin from total anthocyanin in three experiments. ${ }^{*} \mathrm{P}<0.05$ vs .each non-addition of polyvinylalcohol.

\subsection{Effect of Polyvinylalcohol on the Stability of Anthocyanin in Aqueous Solution and in the Solid Phase}

To investigate the effect of polyvinylalcohol on the stability of anthocyanin in aqueous solution, it was added to the anthocyanin solution, which was then kept at room temperature for 60 days. As shown in Table 1, polyvinylalcohol did not significantly affect the stability of anthocyanin in the aqueous solution, when it increased up to the concentrtion of $25 \mathrm{mg} / \mathrm{ml}$. In contrast, the stability of the anthocyanin in the solid phase was increased with the concentration of polyvinylalcohol, irrespective of the type of solid phase material (Table 2). In the presence of $1.25 \mathrm{mg}$ polyvinylalcohol, the stability of anthocyanins remained $62.7 \% \pm 3.8 \%$ in the cotton swab ${ }^{\circledR}$, $80.0 \% \pm 4.4 \%$ in the polypropyrene membrane, and $97.9 \% \pm 6.8 \%$ in the Bell oasis ${ }^{\circledR}$ after storage of 60 days. Interestingly, the stability was well maintained after storage for 180 days, showing that it remained $61.5 \% \pm 6.5 \%$ in the cotton swab ${ }^{\circledR}, 78.0 \% \pm 5.4 \%$ in the polypropyrene membrane, and $95.0 \% \pm 11.1 \%$ in the Bell oasis ${ }^{\circledR}$, whereas it remained $40.8 \% \pm 5.0 \%, 44.0 \% \pm 8.7 \%$, and $52.6 \% \pm 8.7 \%$ in the absence of the polyvinylalcohol, respectively (data not shown).

\subsection{Analysis of Surface Morphology of the Polyvinylalcohol-Red Wine Complex on the Polypropylene Membrane}

To determine the mechanism by which the polyvinylalcohol increased the stability of anthocyanin in the solid phase, the surface morphology of the polyvinylalcohol-red wine complexes was analyzed by phase contrast microscopy. As shown in Figure 3, a heterogeneous porous structure was produced by the polyvinylalcohol (1.25 $\mathrm{mg}$ ) and red wine (14 $\mu \mathrm{g}$ of anthocyanin) on the polypropylene membrane. Anthocyanin (dark area) was condensed and immobilized in the polymer structure when it was applied to the polyvinylalcohol-coated film and dried at room temperature for 5 days. On the other hand, the structure of polyvinylalcohol alone distributed all around interconnected pores on the film, and the red wine alone was uniformly covered with small particles.

\subsection{Relationship between Color Changes of Anthocyanins and $\mathrm{pH}$ in the Cotton Swab ${ }^{\circledR}$}

Having shown that polyvinylalcohol stabilizes anthocyanins in the solid phase, we next attempted to supply stable anthocyanins as a visual sensor of $\mathrm{pH}$ indicator in the cotton swab ${ }^{\circledR}$. As shown in Figure 4, the complex of anthocyanin and polyvinylalcohol on the cotton swab ${ }^{\circledR}$ displayed a variety of color variations according to the prevailing $\mathrm{pH}$ (5.5 - 8.0), when it was dipped into buffer solutions with pHs from 5.5 to 9.0. However, no further changes occurred at $\mathrm{pH}$ higher than 8.0. The color of anthocyanin at $\mathrm{pH} 5.5$ - 8.0 was stable at room temperature without light during 2 months but was not when the $\mathrm{pH}$ was 8.5 or higher (data not shown).

\section{Discussion}

We previously reported that the combination of polyvinylalcohol and red wine successfully stabilized anthocyanins of red wine in the solid phase materials such as cotton swab ${ }^{\circledR}$ and inert polymers [12]. This is the first report to 


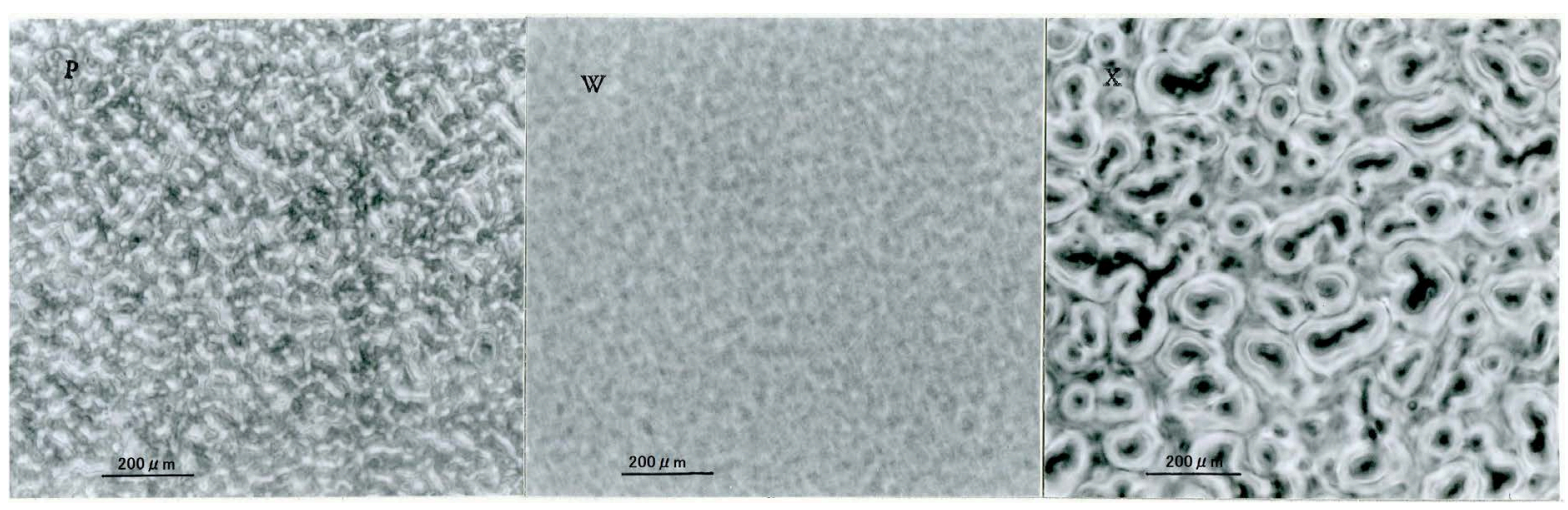

Figure 3. Phase-cntrast microscopy of polyvinylalcohol-red wine complex. $100 \mu$ of polyvinylalcohol (PVA) solution (12.5 $\mathrm{mg} / \mathrm{ml})$ was applied on a square $(2 \times 2 \mathrm{~cm})$ polypropylene membrane and dried at room temperature for 3 days, after which $70 \mu \mathrm{l}$ of red wine (14 $\mu \mathrm{g}$ of anthocyanin) was applied to the surface (diameter: $8.4 \pm 0.2 \mathrm{~mm})$. (P) PVA only; (W) red wine only; (X) PVA + red wine. Bar: $200 \mu \mathrm{m}$.

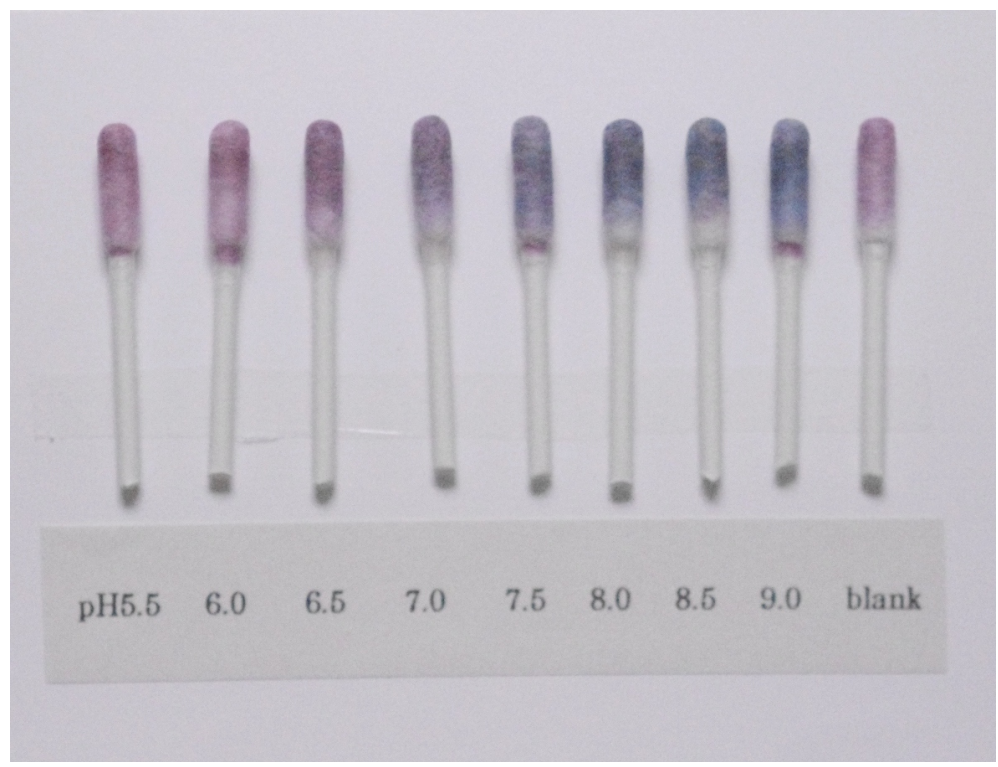

Figure 4. Relationship between color changes of anthocyanin and pH solution in the cotton swab ${ }^{\circledR}$. The cotton swab ${ }^{\circledR}$ was dipped into $100 \mu \mathrm{l}$ of $0.15 \mathrm{M}$ phosphate (pH 5.5 - 8.0) and/or $0.15 \mathrm{M}$ carbonate/bicarbonate buffer (pH 8.5 - 9.5), and then a photograph was taken. Blank: native cotton $\mathrm{swab}^{\circledR}$ as a pH indicator. Other experimental conditions are described in the text.

be analyzed by phase contrast microscopy of the surface morphology in the polyvinylalcohol-red wine complexes by which mechanism polyvinylalcohol stabilizes anthocyanins of young red wine. Anthocyanins are highly unstable and easily susceptible to degradation, because the three species of water $\left(\mathrm{H}^{+}, \mathrm{OH}^{-}\right.$and $\left.\mathrm{H}_{2} \mathrm{O}\right)$ are highly reactive towards them. To overcome this problem, several investigators attempted to stabilize anthocyanins by polyacylation, metal-binding, and their interaction with polysaccharides [15]-[19]. However, the stabilization was not sufficient as it depended on the storage period, $\mathrm{pH}$ and temperature. Bimpilas et al. reported that, during 1 year of storage, monomeric anthocyanins declined by almost tenfold, probably due to polymerization reactions and copigmentation [4]. Therefore, we prepared young red wine from Cambell Early grapes to obtain an abundance of monomeric anthocyanins, finding that monomeric anthocyanins such as cyanidin-3-glucoside and malvidin-3-glucoside represented approximately $43.6 \%$ of total anthocyanins, unlike in commercial wine for storage [4]. We next attempted to stabilize the anthocyanins in the solid phase using the young red wine and polyvinyl alcohol on materials such as a cotton swab ${ }^{\circledR}$ and inert materials. Unlike in aqueous solution, anthocyanin in the solid phase was stable in storage for 180 days at room temperature. Interestingly, the stability of the anthocyanins increased with the concentration of polyvinylalcohol in the solid phase but not in the aqueous solution. To 
determine the mechanism by which this occurred, we analyzed the surface morphology of polyvinylalcohol-anthocyanin complexes by phase-contrast microscopy. Interestingly, the anthocyanins in the complexes were found to be condensed and immobilized in polyvinylalcohol polymer structures. This result seemed to reflect the finding of He et al. that the stability of anthocyanins was affected by their concentrations and surroundings [13]. Therefore, monomeric anthocyanins in red young wine seemed to be condensed by polyvinylalcohol into the solid phase, probably due to the formation of hydrogen bonds from the hydroxyl group of polyvinylalcohol and protonated flavylium cations of the anthocyanin. However, further studies will be necessary to clarify the exact mechanism for the stabilization of anthocyanins at different pHs. Our project goal is to supply stable anthocyanins as a visual indicator for clinical measurement of $\mathrm{pH}$, because anthocyanins display a variety of colors with variations in $\mathrm{pH}$ [1]-[4] and are safe to use [19] [20]. Recently, using a $\mathrm{pH}$ meter or $\mathrm{pH}$ tape, several investigators have shown that salivary $\mathrm{pH}$ plays important roles in oral diseases [21] and systemic diseases [22], and that nasal $\mathrm{pH}$ becomes more alkaline in allergic rhinitis [23]. However, these measurements remain difficult to perform at frequent intervals with a $\mathrm{pH}$ meter, and saliva must be collected prior to the measurement of salivary $\mathrm{pH}$, because the chemical components of the $\mathrm{pH}$ indicator tape may be carcinogenic [24]. As expected, the cotton $\mathrm{swab}^{\circledR}$ revealed a variety of colors at different $\mathrm{pHs}$ due to changes of the molecular structure caused by the ionic nature of anthocyanins [1] [3]. These results suggest that anthocyanins from red wine stabilized in the solid phase by polyvinylalcohol can be used as a visual indicator of $\mathrm{pH}$. Fortunately, the stability of anthocyanins in the presence of $1.25 \mathrm{mg}$ of polyvinylalcohol on a cotton swab $^{\circledR}$ remained $62.7 \% \pm 3.8 \%$ and $61.5 \% \pm 6.5 \%$ after storage for 60 days and 180 days, respectively. Therefore, further studies expect to be clarified relationship between clinical measurement of $\mathrm{pH}$ and an assay system using anthocyanins stablized in the solid phase by the complex of young red wine and polyvinylalcohol.

\section{Acknowledgements}

This work was supported by JSPS KAKENHI funds from a Grant-in-Aid for Scientific Research (No. 26463153) to coauthor T.K.

\section{Conflict of Interest}

The authors declare that there is no conflict of interest regarding the publication of this paper.

\section{References}

[1] Eiro, M.J. and Heinonen, M. (2002) Anthocyanin Color Behavior and Stability during Storage: Effect of Intermolecular Copigmentation. Journal of Agricultural and Food Chemistry, 50, 7461-7466. http://dx.doi.org/10.1021/jf0258306

[2] Mazza, G. and Francis, F.J. (1995) Anthocyanins in Grapes and Grape Products. Critical Reviews in Food Science and Nutrition, 35, 341-371. http://dx.doi.org/10.1080/10408399509527704

[3] Lopes, P., Richard, T., Saucier, C., Teissedre, P.L., Monti, J.P. and Glories, Y. (2007) Anthocyanone A: A Quinine Methide Derivative Resulting from Malvidin 3-O-Glucoside Degradation. Journal of Agricultural and Food Chemistry, 55, 2698-2704. http://dx.doi.org/10.1021/jf0628750

[4] Bimpilas, A., Tsimogiannis, D., Brouma, K.B., Lymperopoulou, T. and Oreopoulou, V. (2015) Evolution of Phenolic Compounds and Metal Content of Wine during Alcoholic Fermentation and Storage. Food Chemistry, 178, $164-171$. http://dx.doi.org/10.1016/j.foodchem.2015.01.090

[5] Mateus, N., Sivia, A.M.S., Vercauteren, J. and de Freitas, V.J. (2001) Occurrences of Anthocyanin-Derived Pigments in Red Wines. Journal of Agricultural and Food Chemistry, 49, 4836-4840. http://dx.doi.org/10.1021/jf001505b

[6] Saxena, S.K. (2003) Polyvinyl Alcohol (PVA) Chemical and Technical Assessment. The Joint FAO/WHO Expert Committee on Food Additives, 61st Meeting, Rome, 10-19 June 2003, 1-3.

[7] Kim, J.O., Park, J.K., Kim, J.H., Jin, S.G., Yong, C.S., Li, D.X., et al. (2008) Development of Polyvinylalcohol-Sodium Alginate Gel-Matrix-Based Wound Dressing System Containing Nitrofurazone. International Journal of Pharmaceutics, 359, 79-86. http://dx.doi.org/10.1016/j.ijpharm.2008.03.021

[8] Srinivasa, P.C., Ramesh, M.N., Kumar, K.R. and Tharanathan, RN. (2003) Properties and Sorption Studies of Chitosan-Polyvinylalcohol Blend Films. Carbohydrate Polymers Carbohyd Polym, 53, 431-438. http://dx.doi.org/10.1016/S0144-8617(03)00105-X

[9] Danwanichakuk, P. and Sirikhajornnam, P. (2013) An Investigation of Chitosan-grafted-poly(vinyl alcohol) as an Electrolyte Membrane. Journal of Chemistry, 2013, Article ID: 642871. 
[10] Conte, A., Buonocore, G.G., Bevilacqua, A., Sinigaglla, M. and Nobile, M.A.D. (2006) Immobilization of Lysozyme on Polyvinylalcohol Films for Active Packaging Applications. Journal of Food Protection, 69, 866-870.

[11] Singh, V. and Mishra, A.K. (2015) White Light Emission from Vegetable Extracts. Scientific Reports, 5, Article ID: 11118. http://dx.doi.org/10.1038/srep11118

[12] Sakamoto, W., Kanehira, T., Hongou, H., Matsuda, A., Mune, M., et al. (2015) Application of Color Changes of Anthocyanins in Red Wine and Red Currant Extract as a Clinical pH Indicator. Journal of Diagnostic Techniques and Biomedical Analysis, 2, 2.

[13] He, F., Liang, N.N., Mu, L., Pan, Q.H., Wang, J., Reeves, M.J. and Duan, C.-Q. (2012) Anthocyanins and Their Variation in Red Wines. I. Monomeric Anthocyanins and Their Color Expression. Molecules, 17, 1571-1601. http://dx.doi.org/10.3390/molecules17021571

[14] Lee, J., Durst, R.W. and Wrolstad, R.E. (2005) Determination of Total Monomeric Anthocyanin Pigment Content of Fruit Juices, Beverages, Natural Colorants, and Wines by the pH Differential Method: Collaborative Study. Journal of AOAC International, 88, 1269-1278.

[15] Lewis, C.E., Walker, J.R.L. and Lancaster, J.E. (1995) Effect of Polysaccharides on the Colour of Anthocyanins. Food Chemistry, 54, 315-319. http://dx.doi.org/10.1016/0308-8146(95)00026-F

[16] Tachibana, N., Kimura, Y. and Ohno, T. (2014) Examination of Molecular Mechanism for the Enhanced Thermal Stability of Anthocyanins by Metal Cations and Polysaccharides. Food Chemistry, 143, 452-458. http://dx.doi.org/10.1016/j.foodchem.2013.08.017

[17] Buchweitz, M., Speth, M., Kammerer, D.R. and Carle, R. (2013) Stabilisation of Strawberry (Fragaria x ananassa Duch.) Anthocyanins by Different Pectins. Food Chemistry, 141, 2998-3006. http://dx.doi.org/10.1016/j.foodchem.2013.04.117

[18] Nour, V., Trandarfir, I. and Ionica, M.E. (2011) Ascorbic Acid, Anthocyanins, Organic Acids and Mineral Content of Some Black and Red Currant Cultivars. Fruits, 66, 353-362. http://dx.doi.org/10.1051/fruits/2011049

[19] Kruger, M.J., Davies, N., Myburgh, K.H. and Lecour, S. (2014) Proanthocyanins, Anthocyanins and Cardiovascular Diseases. Food Research International, 59, 41-52. http://dx.doi.org/10.1016/j.foodres.2014.01.046

[20] Pojer, E., Mattivi, F., Johnson, D. and Stockley, C.S. (2013) The Case for Anthocyanin Consumption to Promote Human Health: A Review. Comprehensive Reviews in Food Science and Food Safety, 12, 483-508. http://dx.doi.org/10.1111/1541-4337.12024

[21] Baliga, S., Muglikar, S. and Kate, R. (2013) Salivary pH: A Diagnostic Biomarker. Journal of Indian Society of Periodontology, 17, 461-465. http://dx.doi.org/10.4103/0972-124X.118317

[22] Mahesh, D.R., Komli, G., Jayanthi, K., Dinesh, D., Saikavitha, T.V., et al. (2014) Evaluation of Salivary Flow Rate, $\mathrm{pH}$ and Buffer in Pre, Post and Post Menopausal Women on HRT. Journal of Clinical and Diagnostic Research, 8, 233-236.

[23] England, R.J., Homer, J.J., Knight, L.C. and Ell, S.R. (1999) Nasal pH Measurement: A Reliable and Repeatable Parameter. Clinical Otolaryngology and Allied Science, 24, 67-68. http://dx.doi.org/10.1046/j.1365-2273.1999.00223.x

[24] Cooper, G.S., Longnecker, M.P. and Peters, R.K. (2004) Ovarian Cancer Risk and Use of Phenolphthalein-Containing Laxatives. Pharmacoepidemiology and Drug Safety, 13, 35-39. http://dx.doi.org/10.1002/pds.824 